\title{
PENGARUH KESADARAN KESEHATAN DAN PRODUK MAKANAN TERHADAP MINAT BELI RESTORAN VEGETARIAN DENGAN VARIABEL MODERASI RELIGIUSITAS DI INDONESIA
}

\author{
Himawan \\ Program Studi Magister Manajemen Universitas Tarumanagara \\ himawanxxwy@gmail.com \\ Hetty Karunia Tunjungsari \\ Program Studi Magister Manajemen Universitas Tarumanagara
}

\begin{abstract}
This study aims to determine the characteristics of vegetarian restaurant consumers and to determine the effect of health consciousness and food product on purchase intention at vegetarian restaurant partially in Indonesia. This Study also determine the effect of health consciousness on the relationship with religiosity and the effect of food product on the relationship with religiosity with an purchase intention at vegetarian restaurant in Indonesia.

This research uses descriptive quantitative methods. The method of data collection is done using primary data and secondary data. Primary data is obtained from the distribution of questionnaires while secondary data is obtained from other sources. Furthermore, the population in this study were vegetarian restaurant consumers in 5 major cities of Indonesia namely Jakarta, Bandung, Semarang, Surabaya, Medan. This study uses non-probability sampling techniques by taking purposive sampling. The number of samples in this study were 382 respondents. The method of data analysis in this study used multiple regression analysis with the SmartPLS version 3.0 program.

The results of this study indicate that health consciousness and food product have a significant influence on purchase intention at vegetarian restaurant partially. Health consciousness and food products have a significant influence on purchase intention which is moderated by religiosity in vegetarian restaurant customers. Furthermore Health consciousness and product to purchase intention will be further strengthened if moderated by religiosity.
\end{abstract}

Abstrak : Penelitian ini bertujuan untuk mengetahui karakteristik konsumen restoran vegetarian dan untuk mengetahui pengaruh kesadaran kesehatan dan produk makanan pada minat beli restoran vegetarian secara parsial di Indonesia. Studi ini juga menentukan pengaruh kesadaran kesehatan pada hubungan dengan religiusitas dan efek produk makanan pada hubungan dengan religiusitas dengan minat beli restoran vegetarian di Indonesia.

Penelitian ini menggunakan metode deskriptif kuantitatif. Metode pengumpulan data dilakukan menggunakan data primer dan data sekunder. Data primer diperoleh dari distribusi kuesioner sedangkan data sekunder diperoleh dari sumber lainnya. Selanjutnya, populasi pada penelitian adalah konsumen restoran vegetarian yang tersebar pada 5 kota besar di Indonesia yaitu Jakarta, Bandung, Semarang, Surabaya dan Medan. Penelitian ini menggunakan teknik non-probability sampling dengan cara pengambilan purposive sampling. Jumlah sampel dalam penelitian ini adalah 382 responden. Metode analisis data penelitian ini menggunakan analisis regresi berganda dengan program SmartPLS versi 3.0.

Hasil penelitian ini menunjukkan bahwa kesadaran kesehatan dan produk makanan memiliki pengaruh yang signifikan terhadap minat beli restoran vegetarian secara parsial. Kesadaran kesehatan dan produk makanan memiliki pengaruh yang signifikan terhadap minat beli restoran vegetarian yang dimoderasi oleh religiusitas. Selanjutnya kesadaran kesehatan dan produk makanan terhadap minat beli akan lebih diperkuat jika dimoderasi oleh religiusitas. 
Keywords: Health Consciousness, Products, Religiosity, Purchase Intention, Regression, Moderate, SmartPLS

\section{PENDAHULUAN \\ Latar Belakang}

Sektor kuliner saat ini telah mengalami perkembangan begitu pesat. Perkembangan bisnis restoran semakin hari semakin terlihat banyak untuk diminati. Hal ini didukung dengan survey dari The Nielsen Company yang menyatakan bahwa $44 \%$ dari orang Indonesia menyukai makan di luar rumah atau di restoran. Hal tersebut diiringi dengan fakta bahwa seseorang terutama yang telah bekerja lebih memilih untuk membeli makan diluar daripada makan dirumah atau memasak untuk menghemat waktu mereka (Pakna, 2016). Meningkatnya konsumsi makanan diluar rumah berdampak pada peningkatan asupan kalori, lemak jenuh, gula tambahan, dan sodium, dan menurunnya konsumsi buah dan sayuran, dan serat kurang, dan vitamin (Kant \& Graubard, 2004; Schmidt et al., 2005). Maka dari itu restoran vegetarian hadir sebagai salah satu alternatif dalam mengatasi hal tersebut.

Pola makan vegetarian saat ini mulai banyak diikuti oleh banyak kalangan masyarakat di Indonesia. Hal tersebut disebabkan oleh mulai meningkatnya kesadaran masyarakat akan manfaat dalam melakukan pola makan vegetarian. Vegetarian adalah orang yang hidup dari mengkonsumsi produk yang berasal dari tumbuhan (nabati) dengan atau tanpa susu dan telur, tetapi secara keseluruhan menghindari penggunaan daging, unggas dan hewan laut (Melina dan Davis, 2003).

Memilih mengkonsumsi makanan vegetarian memberikan banyak dampak positif bagi kehidupan manusia baik secara individu maupun secara sosial. Dampak utama yang paling dirasakan ketika seseorang menjadi vegetarian adalah kesehatan. Konsumsi makanan vegetarian seperti buah dan sayuran penting bagi kesehatan karena makanan-makanan ini mengandung sumber nutrisi utama yang dibutuhkan mengandung phytochemicals yang dapat menurunkan risiko penyakit kronis (Stahler, 2009). Selain faktor kesehatan perlu juga diperhatikan alasan seseorang memilih restoran adalah karena produk yang ditawarkan restoran tersebut. Perlu diingat salah satu faktor yang mempengaruhi keputusan pembelian dari konsumen adalah produk (Kotler, 2010). Faktor lain yang menjadi pertimbangan seseorang memilih restoran vegetarian atau menjadi vegetarian adalah faktor religiusitas. Ada beberapa agama atau kepercayaan di dunia ini yang menganjurkan umatnya untuk menjadi seorang vegetarian (Susianto, 2007). Melihat latar belakang tersebut maka peneliti tertarik untuk melakukan penelitian dengan judul "Pengaruh Kesadaran Kesehatan dan Produk Makanan Terhadap Minat Beli Restoran Vegetarian dengan Variabel Moderasi Religiusitas di Indonesia".

\section{Tujuan Penelitian}

Berdasarkan latar belakang dan pokok yang telah dijabarkan diatas, maka tujuan dari penelitian ini adalah :

- Mengetahui karakteristik konsumen restoran vegetarian.

- Mengetahui pengaruh kesadaran kesehatan, produk makanan terhadap minat beli restoran vegetarian secara parsial.

- Mengetahui pengaruh kesadaran kesehatan dan produk makanan apabila dimoderasi dengan religiusitas terhadap minat beli restoran vegetarian. 


\section{TINJAUAN PUSTAKA}

\section{Kesadaran Kesehatan, Produk, Religiusitas dan Minat Beli}

Hong menyatakan bahwa kesadaran kesehatan adalah kesadaran berdasarkan persepsi kesehatan sebagai individu, dengan tanggung jawab dan motivasi agar menjadi sehat (Hong, 2011). Produk adalah semua hal yang dapat ditawarkan kepada pasar untuk menarik perhatian, akuisisi, penggunaan atau konsumsi yang dapat memuaskan suatu keinginan atau kebutuhan (Kotler, 2010). Religiusitas adalah suatu kewajiban-kewajiban atau aturan-aturan yang harus dilaksanakan, yang kesemuanya itu berfungsi untuk mengikat dan mengutuhkan diri seseorang atau sekelompok orang dalam hubungannya dengan Tuhan atau sesama manusia, serta alam sekitar (Drikarya, 1987). Minat beli merupakan bagian dari komponen perilaku dalam sikap mengkonsumsi. Menurut Kinnear dan Taylor minat membeli adalah merupakan bagian dari komponen perilaku konsumen dalam sikap mengkonsumsi, kecenderungan responden untuk bertindak sebelum keputusan membeli benar-benar dilaksanakan.

\section{Penelitian Terdahulu}

Penelitian yang dilakukan oleh Chia-Hsin Cheng, Shih-Yen Lin, Chia-Ching Tsai, dengan judul penelitian Investigating Consumer Preferences in Choosing Vegetarian Restaurants Using Conjoint Analysis (2014). Penelitian tersebut menyatakan faktor yang mendorong konsumen dalam memilih restaurant vegetarian adalah kualitas makanan, gaya masakan, konsep kesehatan, design restaurant, kepedulian terhadap lingkungan. Penelitian ini menggunakan analisis konjoin. Hasil penelitian menyatakan bahwa faktor utama yang mendorong orang datang ke restaurant vegetarian adalah kualitas makanan dengan persentase $34,62 \%$. Faktor kedua yaitu kepedulian terhadap lingkungan yaitu sebesar 17,27 \%. Faktor ketiga adalah gaya masakan sebesar $16,85 \%$. Faktor keempat adalah design restaurant dengan persentase 15,95\%. Dan faktor terakhir adalah alasan kesehatan sebesar 15,3\%.

Pada penelitian yang dilakukan Peter Pribis, Rose C Pencak, dan Tevni Grajales (2010) dengan judul penelitian Beliefs and Attitudes toward Vegetarian Lifestyle across Generations. Penelitian dilakukan dengan menggunakan metode one way ANOVA. Hasil penelitian menunjukan bahwa kelompok yang berada di usia 11-20 tahun cenderung menjadi vegetarian karena alasan moral dan lingkungan. Kelompok yang berada di usia 41-60 tahun cenderung memilih vegetarian karena alasan kesehatan. Kelompok yang di usia diatas 60 tahun cenderung memilih vegetarian karena alasan keyakinan.

\section{METODOLOGI PENELITIAN}

Penelitian tentang Pengaruh Kesadaran Kesehatan dan Produk Terhadap Minat Beli Restoran Vegetarian dengan Variabel Moderasi Religiusitas menggunakan metode penelitian deskriptif kuantitatif. Model penelitian deskriptif bertujuan untuk menghimpun data gambaran karakteristik konsumen restoran vegetarian. Sedangkan Penelitian dilakukan secara kuantitatif agar dapat dilakukan analisis statistik (Sulistyo, 2006). Untuk operasional variabel pada penelitian ini yaitu:

- Kesadaran Kesehatan (X1)

> Integrasi perilaku kesehatan: memiliki rasa takut untuk sakit, memperhatikan kebugaran fisik atau menghindari kegemukan dan memperhatikan gizi makanan yang dikonsumsi.

$>$ Pencari dan pengguna informasi, dan motivasi kesehatan: Mencari informasi gizi dari makanan yang dikonsumsi dan melakuan perawatan dengan mencegah makan makanan tidak sehat.

- Produk (X2)

$>$ Kuantitas: porsi makanan yang relatif besar 
Kualitas: cita rasa makanan yang nikmat untuk dikonsumsi, Kandungan gizi dalam makanan yang baik, dan tamilan makanan yang menarik.

- Religiusitas (X3)

$>$ Religious Belief: Percaya Tuhan pencipta manusia

$>$ Religious Knowledge: Memiliki pengetahuan akan ajaran agama yang dianut

$>$ Religious Practice: Mengerjakan ajaran yang diajarkan oleh agama

$>$ Religious Feeling: Memiliki rasa takut akan dosa

$>$ Religious Effect: Melestarikan lingkungan alam bentuk kepedulian akibat kepercayaan

- Minat Beli (Y)

$>$ Transaksional: bekerja untuk membeli produk

Refrensial: bersedia untuk merekomendasikan produk

Prefensial: menjadi pilihan utama

$>$ Eksploratif: Ingin mencari informasi tentang produk

Populasi dalam penelitian ini adalah konsumen restoran vegetarian di Indonesia. Penelitian ini menggunakan teknik non-probability sampling dengan cara pengambilan sampling purposive. Populasi yang terdapat pada penelitian ini berjumlah 19.537.041 yaitu jumlah penduduk di Jakarta, Bandung, Semarang, Surabaya dan Medan per 2016. Metode analisis data dalam penelitian ini menggunakan analisis regresi berganda (multiple regression analysis) dengan program SmartPLS versi 3.0.

\section{HASIL DAN KESIMPULAN}

\section{Hasil Pengujian Regresi Berganda}

Pada Penelitian ini model yang digunakan adalah model analisis regresi berganda dengan variable moderasi. Dengan persamaan awal sebagai berikut.

$\mathrm{Y}=\alpha+\beta 1 \mathrm{X} 1+\beta 2 \mathrm{X} 2+\beta 3 \mathrm{X3}+\beta 4 \mathrm{X} 4+\beta 5 \mathrm{X} 5+\mathrm{e}$

Keterangan :

$\mathrm{Y}=$ Minat Beli

$\alpha=$ Konstanta

$\beta=$ Koefisien regresi yang menunjukkan angka peningkatan atau penurunan variabel dependen yang didasarkan pada variabel independen

$\mathrm{X} 1$ = Kesadaran Kepuasan

$\mathrm{X} 2$ = Produk

$\mathrm{X} 3$ = Religuisitas

$\mathrm{X} 4=|\mathrm{X} 1-\mathrm{X} 3| \quad=$ Interaksi antara $\mathrm{X} 1$ dan $\mathrm{X} 3$

$\mathrm{X} 5=|\mathrm{X} 2-\mathrm{X} 3| \quad=$ Interaksi antara $\mathrm{X} 2$ dan $\mathrm{X} 3$

$\varepsilon=$ Kesalahan penggangu (error)

Pengujian analisis regresi berganda dibantu dengan menggunakan program Smart PLS versi 3. Model yang digunakan dapat dilihat pada Gambar 1. 


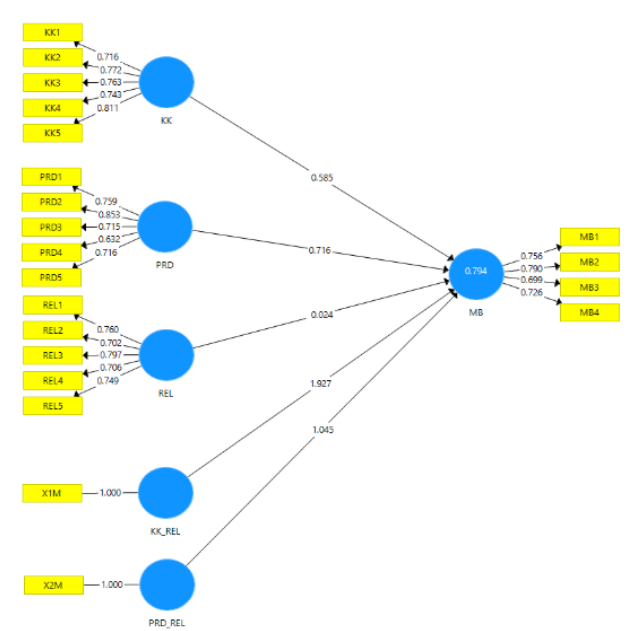

Gambar

Sumber: Hasil Olahan Data PLS 3.0 (2018)

Path Model Analisis Regresi dengan Program Smart PLS 3.0

Dengan Tingkat signifikansi $(\alpha)$ yang digunakan adalah sebesar 5\% $(0,05)$. Hasil uji regresi berganda dapat dilihat pada output gambar dan tabel dibawah ini.

Tabel 2. Hasil Uji Regresi Berganda

\begin{tabular}{|l|c|r|r|r|r|}
\hline & $\begin{array}{c}\text { Original } \\
\text { Sample } \\
(\mathbf{O})\end{array}$ & $\begin{array}{c}\text { Sample } \\
\text { Mean (M) }\end{array}$ & $\begin{array}{l}\text { Standard } \\
\text { Deviation } \\
\text { (STDEV) }\end{array}$ & $\begin{array}{c}\text { T Statistics } \\
(\mid \mathbf{O} / \text { STDEV|) }\end{array}$ & $\begin{array}{c}\text { P } \\
\text { Values }\end{array}$ \\
\hline KK $\rightarrow$ MB & 0.585 & 0.552 & 0.146 & 3.999 & 0.000 \\
\hline $\begin{array}{l}\text { KK_REL } \\
\rightarrow \text { MB }\end{array}$ & 1.927 & 1.867 & 0.269 & 7.175 & 0.000 \\
\hline $\begin{array}{l}\text { PRD } \\
\rightarrow \text { MB }\end{array}$ & 0.716 & 0.725 & 0.142 & 5.061 & 0.000 \\
\hline $\begin{array}{l}\text { PRD_REL } \\
\rightarrow \text { MB }\end{array}$ & 1.045 & 1.060 & 0.227 & 4.612 & 0.000 \\
\hline $\begin{array}{l}\text { REL } \rightarrow \\
\text { MB }\end{array}$ & 0.024 & 0.016 & 0.153 & 0.159 & 0.874 \\
\hline
\end{tabular}

Sumber: Hasil Olahan Data PLS 3.0 (2018)

Berdasarkan hasil analisis regresi berganda dengan menggunakan program Smart PLS 3.0, maka persamaan regresi yang dimunculkan adalah sebagai berikut.

$$
\mathrm{Y}=0,794+0,585 \mathrm{X} 1+0,716 \mathrm{X} 2+0,024 X 3+1,927 \mathrm{X} 4+1,045 \times 5+\mathrm{e}
$$

Setelah mendapatkan hasil regresi didapatkan nilai R2 (Koefisien determinasi) pada penelitian ini adalah 0,791. Artinya bahwa kemampuan variabel bebas dalam menjelaskan varians dari variabel terikatnya adalah sebesar $79,1 \%$. Sehingga $20,9 \%$ varians variabel terikat (minat beli) dijelaskan oleh factor lain.

\section{Hasil Pengujian Hipotesis}

Dari hasil di tabel 2 di atas maka disimpulkan untuk masing-masing hasil hipotesis sebagai berikut:

\section{Hipotesis 1: Terdapat pengaruh kesadaran kesehatan terhadap minat beli restoran vegetarian}

Berdasarkan Tabel 2, hasil hipotesis pertama pada variabel kesadaran kesehatan (KK) terhadap minat beli $(\mathrm{MB})$ di restoran vegetarian menghasilkan nilai t-hitung sebesar 3,973 > t-tabel 1,966 dengan nilai signifikan sebesar 0,000 < 0,05. Dengan demikian H1 diterima 
dalam penelitian ini. Dapat disimpulkan bahwa variabel kesadaran kesehatan (KK) memiliki pengaruh yang signifikan terhadap minat beli (MB) pelanggan restoran vegetarian.

\section{Hipotesis 2: Terdapat pengaruh produk terhadap minat beli restoran vegetarian}

Berdasarkan Tabel 2, hasil hipotesis kedua pada variabel produk (PRD) terhadap minat beli (MB) di restoran vegetarian menghasilkan nilai t-hitung sebesar 5,312 > t-tabel 1,966 dengan nilai signifikan sebesar 0,000 $<0,05$. Dengan demikian H2 diterima dalam penelitian ini. Dapat disimpulkan bahwa variabel produk (PRD) memiliki pengaruh yang signifikan terhadap minat beli (MB) pelanggan restoran vegetarian.

\section{Hipotesis 3: Terdapat pengaruh kesadaran kesehatan terhadap minat beli restoran vegetarian dengan dimoderasi oleh religiusitas}

Berdasarkan Tabel 2, hasil hipotesis ketiga pada variabel kesadaran kesehatan (KK) terhadap minat beli (MB) pada pelanggan restoran vegetarian melalui religiusitas (REL) sebagai variabel moderasi menghasilkan nilai t-hitung sebesar 7,245>t-tabel 1,966 dengan nilai signifikan sebesar $0,000<0,05$. Dengan demikian H3 diterima dalam penelitian ini. Dapat disimpulkan bahwa variabel kesadaran kesehatan memiliki pengaruh yang signifikan terhadap minat beli dengan dimoderasi oleh religiusitas pada pelanggan restoran vegetarian.

\section{Hipotesis 4: Terdapat pengaruh produk terhadap minat beli restoran vegetarian dengan dimoderasi oleh religiusitas}

Berdasarkan Tabel 2, hasil hipotesis ketiga pada variabel produk (PRD) terhadap minat beli (MB) pada pelanggan restoran vegetarian melalui religiusitas (REL) sebagai variabel moderasi menghasilkan nilai t-hitung sebesar 4,896 > t-tabel 1,966 dengan nilai signifikan sebesar 0,000 < 0,05. Dengan demikian H4 diterima dalam penelitian ini. Dapat disimpulkan bahwa variabel produk memiliki pengaruh yang signifikan terhadap minat beli dengan dimoderasi oleh religiusitas pada pelanggan restoran vegetarian.

\section{Hasil pembahasan}

Berdasarkan hasil penelitian yang telah dilakukan, diketahui bahwa variabel kesadaran kesehatan dan produk memiliki pengaruh yang signifikan terhadap minat beli di restoran vegetarian tanpa dimoderasi oleh religiusitas. Kemudian variabel kesadaran kesehatan dan produk memiliki pengaruh yang signifikan terhadap minat beli yang dimoderasi oleh religiusitas pada pelanggan restoran vegetarian. Kesadaran kesehatan sebagai suatu kondisi kesadaran seseorang atas persepsi kesehatan sebagai individu, dengan tanggung jawab dan motivasi agar menjadi sehat (Hong, 2011) memberikan dampak yang kuat atau pengaruh yang kuat terhadap minat individu tersebut untuk mengkonsumsi vegetarian. Oleh sebab itu, minat beli konsumen atas produk vegetarian dipengaruhi langsung oleh tingkat kesadaran individu atas kesehatan. Hasil penelitian ini sejalan dengan temuan penelitian Syaifulloh dan Iriani (2013) yang menunjukkan bahwa gaya hidup sehat sebagai suatu bentuk kesadaran dari individu pentingnya kesehatan memiliki pengaruh siginifikan terhadap minat membeli produk-produk organik atau makanan dan minuman sehat. Penelitian terdahulu yang dilakukan oleh Knutson dan Patton (1993) dalam Cheng et.al. (2014) yang menemukan bahwa banyak konsumen yang semakin khawatir tentang diet kesehatan dapat membantu menurunkan berat badan sehingga memilih untuk mengkonsumsi vegetarian.

Berdasarkan hasil penelitian dengan menjadikan religiusitas sebagai variabel pemoderasi variabel kesadaran kesehatan, tebukti bahwa kesadaran kesehatan memiliki pengaruh signifikan terhadap terhadap minat beli yang dimoderasi oleh religiusitas pada pelanggan restoran vegetarian. Bahkan pengaruh yang ditimbulkan akibat variabel tersebut dimoderasi adalah semakin kuat. Hal tersebut tentunya sejalan dengan penelitian Peter Pribis 
(2010) bahwa beberapa kelompok usia individu memilih untuk menjadi vegetarian karena alasan moral, lingkungan dan keyakinan

Produk terbukti memiliki pengaruh terhadap pengaruh yang signifikan terhadap minat beli di restoran vegetarian tanpa adanya moderasi oleh religiusitas. Kondisi ini mengindikasikan bahwa produk sebagai sesuatu yang dapat memberikan manfaat, memenuhi kebutuhan konsumen dan dapat memuaskan konsumen (Kotler, 2010) memberikan kontribusi terhadap minat seseorang untuk beli atau berkunjung ke restoran vegetarian. Adanya pengaruh signifikan dari variabel produk terhadap minat beli pada restoran vegetarian tanpa dimoderasi oleh religiusitas dikarenakan produk dapat sepenuhnya merubah perilaku pembelian konsumen terhadap produk vegetarian. Hal tersebut juga mengindikasikan bahwa rasa unik yang dihasilkan dati produk-produk yang ditawarkan serta bahan-bahan berkualitas menjadikan salah satu indikator penentu timbulnya minat seseorang untuk membeli dan atau berkunjung ke suatu restoran vegetarian (Azim et.al., 2014).

Hasil penelitian juga menunjukkan bahwa pengaruh produk terhadap minat beli di restoran vegetarian juga akan menjadi lebih kuat dengan adanya faktor pendorong seperti religiusitas. Dimana hasil penelitian ini menunjukkan bahwa produk memiliki pengaruh signifikan apabila dimoderasi oleh religiusitas. Religiusitas sebagai penghayatan dan pengalaman individu terhadap ajaran agama atau kepercayaan yang dianutnya (Drikarya, 1987), sehingga dapat menjadi pendorong seseorang untuk melakukan pembelian produk pada restaurant vegetarian. Karena pada produk vegetarian, konsumennya sangat tersegmentasi dengan artian tidak semua orang mengkonsumsi produk vegetarian. Oleh sebab itu, hasil penelitian ini memperlihatkan bahwa minat beli seseorang di restoran vegetarian akan meningkat apabila dipicu dengan adanya dorongan dari tingkat religiusitas.

\section{KESIMPULAN}

Berdasarkan hasil pengujian data dan pembahasan pada bab sebelumnya serta menjawab masalah dalam penelitian ini, maka dapat dibuatkan kesimpulan penelitian sebagai berikut:

- Kesadaran kesehatan memiliki pengaruh signifikan terhadap minat beli restoran vegetarian.

- Produk makanan memiliki pengaruh signifikan terhadap minat beli restoran vegetarian.

- Kesadaran kesehatan memiliki pengaruh signifikan terhadap minat beli restoran vegetarian dengan dimoderasi oleh religiusitas.

- Produk makanan memiliki pengaruh signifikan terhadap minat beli restoran vegetarian dengan dimoderasi oleh religiusitas

- Pengaruh kesadaran kesehatan dan produk makanan terhadap minat beli restoran vegetarian akan semakin diperkuat apabila dimoderasi dengan Religiusitas

\section{DAFTAR PUSTAKA}

Cheng, Chia-Hsin, Lin, Shih-Yen, \& Tsai, Chia-Ching. (2014). Current Urban Studies. Investigating Consumer Preferences in Choosing Vegetarian Restaurants Using Conjoint Analysis, 2, 279-290.

Drikarya, N. (1987). Percikan Filsafat. Jakarta : PT. Pembangunan.

Hong, H. (2011). Health Communication. An Extension Of The Extended Parallel Process Model (Eppm) In Television Health News : The Influence Of Health Consciousness On Individual Message Processing And Acceptance, 26, 343-353.

Kant, A. K., \& Graubard, B. I. (2004). Eating out in America, 1987-2000: Trends and Nutritional Correlates. Preventive Me- dicine, 38, 243-249

Kotler, Philip dan Gary Armstrong. (2010). Principles of Marketing (13 ${ }^{\text {th }}$ ed). United States. 
Melina, V. dan Davis, B. (2003). Becoming Vegetarian : The Complete Guide to Adopting a Healthy Vegetarian Diet. Canada : Wiley.

Pakna, Tanyalak dan Suriyapa, Chairat. (2016). Factor of Customers Choice for Chabuton Ramen Restaurant at Terminal 21 Branches. Indian Journal of Commerce and Management Studies, 2249-0310.

Pribis, P., Pencak, R.S., Grajales, T. (2010) Belief and Attitudes toward Vegetarian Lifestyle Across Generation. Nutrient, 2, 521-531

Stahler, C. (2009). How Many Vegetarians Are There. Vegetarian Journal, 4, 6-9.

Sulistyo-Basuki. (2006). Metode Penelitian. Jakarta: Wedatama Widya Sastra dan Fakultas Ilmu Pengetahuan Budaya Universitas Indonesia.

Susianto, Drs., Widjaja, Hendry, dr., Mailoa, Helda, SST Gizi., (2007), Diet Enak Ala Vegetarian. Jakarta : Penebar Plus. 
